\title{
Induction of anesthesia does not alter tricuspid annular velocities: a tissue Doppler assessment
}

\section{L'induction de l'anesthésie ne modifie pas les vélocités de l'anneau tricuspide: une évaluation à l'aide du Doppler tissulaire}

\author{
Claude Tousignant, MD · Richard Bowry, MBBS · \\ Jorge D. Cruz, MD · C. David Mazer, MD
}

Received: 30 April 2009/Accepted: 15 July 2009/Published online: 29 July 2009

(C) Canadian Anesthesiologists' Society 2009

\begin{abstract}
Purpose In this prospective observational cohort study, we investigated whether tricuspid annular velocities (TAV) are altered after induction of anesthesia in patients undergoing coronary artery bypass graft $(C A B G)$ surgery. Methods Twenty-four elective CABG patients were assessed before and after induction of anesthesia, and a convenience sample of nine healthy volunteers was used for comparison of TAV only. Measurements included mean arterial pressure (MAP), heart rate $(H R)$, pulmonary artery pressure (PAP), and cardiac index $(\mathrm{CI})$ as assessed post-induction. Tricuspid annular plane systolic excursion (TAPSE) was measured in anatomical M-mode. The $S$ (systolic) wave velocity and isovolemic acceleration (IVA) were measured from colour tissue Doppler (TD). Paired and unpaired Student's $t$ tests were used to compare all variables pre-and post-induction.
\end{abstract}

Results In response to anesthetic induction, MAP decreased from $105 \pm 14$ to $79 \pm 9 \mathrm{mmHg}$, but HR was unchanged $\left(67 \pm 13\right.$ beats $\cdot \mathrm{min}^{-1}$ pre-induction compared with $67 \pm 9$ beats $\cdot$ min $^{-1}$ post-induction). The mean PAP and CI post-induction were $20 \pm 6 \mathrm{mmHg}$ and $2.3 \pm 0.4$ $L \cdot \min ^{-1} \cdot m^{-2}$, respectively. While there was no change post-induction in either $S$ velocity $(8.80 \pm 1.23$ vs $9.0 \pm 1.92$ $\left.\mathrm{cm} \cdot \mathrm{sec}^{-1}\right)$ or IVA $\left(1.63 \pm 0.61\right.$ vs $\left.1.84 \pm 0.83 \mathrm{~m} \cdot \mathrm{sec}^{-2}\right)$, TAPSE decreased from $23 \pm 4$ to $21 \pm 4 \mathrm{~mm}(P=0.039)$. All pre-induction echocardiographic variables were lower in the CABG group compared with the normal group (IVA: $2.34 \pm 0.34 \mathrm{~m} \cdot \mathrm{sec}^{-2}, \quad S$ wave: $11.14 \pm 2.78 \mathrm{~cm} \cdot \mathrm{sec}^{-1}$, TAPSE 2D: $26 \pm 4 \mathrm{~mm}$ ), respectively.

C. Tousignant, MD $\cdot$ R. Bowry, MBBS $(\varangle)$.

J. D. Cruz, MD - C. D. Mazer, MD

Department of Anesthesia, St Michael's Hospital, University

of Toronto, 30 Bond St, Toronto, ON M5B 1W8, Canada

e-mail: bowryr@smh.toronto.on.ca
Conclusions Induction of anesthesia for $C A B G$ surgery does not alter velocity-based parameters of $R V$ function. There was a small decrease in TAPSE. The TD parameters were lower in $C A B G$ patients compared with the normal group.

\section{Résumé \\ Objectif Dans cette étude de cohorte observationnelle et prospective, nous avons cherché à savoir si les vélocités de l'anneau tricuspide (VAT) se modifiaient après l'induction de l'anesthésie chez des patients subissant un pontage aortocoronarien (PAC).}

Méthode Vingt-quatre patients devant subir un PAC non urgent ont été évalués avant et après l'induction de l'anesthésie et un échantillon de commodité de neuf volontaires sains a été utilisé pour comparer les VAT seulement. Nous avons mesuré la tension artérielle moyenne (TAM), la fréquence cardiaque $(F C)$, la pression artérielle pulmonaire (PAP) et l'index cardiaque (IC) tels qu'évalués après l'induction. L'excursion systolique de l'anneau tricuspide (TAPSE) a été mesurée en mode M anatomique. La vélocité de l'onde S (systolique) et l'accétération isovolémique (AIV) ont été mesurées par Doppler tissulaire (TD). Des tests $t$ de Student appariés et non appariés ont été utilisés pour comparer toutes les variables avant et après l'induction.

Résultats En réaction à l'induction de l'anesthésie, la TAM a diminuéde $105 \pm 14$ à $79 \pm 9 \mathrm{mmHg}$, mais la FC est demeurée stable $\left(67 \pm 13\right.$ battements. $\mathrm{min}^{-1}$ avant par rapport à $67 \pm 9$ battements.min ${ }^{-1}$ après induction). Les PAP et IC moyens après l'induction étaient de : $20 \pm 6$ $\mathrm{mmHg}$ et 2,3 $\pm 0,4 \mathrm{~L} \cdot \mathrm{min}^{-1} \cdot \mathrm{m}^{-2}$, respectivement. Alors qu'il n'y a pas eu de changement de la vélocité $S$ $\left(8,80 \pm 1,23\right.$ et 9,0 $\left.\pm 1,92 \mathrm{~cm} \cdot \mathrm{sec}^{-1}\right)$ ou de l'AIV $(1,63 \pm$ 0,61 et 1,84 $\pm 0,83 \mathrm{~m} \cdot \mathrm{sec}^{-2}$ ) après l'induction, la TAPSE a diminué de $23 \pm 4$ à $21 \pm 4 \mathrm{~mm}(P=0,039)$. Toutes les 
variables échocardiographiques avant l'induction étaient plus basses dans le groupe PAC par rapport au groupe témoin (AIV : 2,34 $\pm 0,34 \mathrm{~m} \cdot \mathrm{sec}^{-2}$, onde $S: 11,14 \pm 2,78$ $\mathrm{cm} \cdot \mathrm{sec}^{-1}$, TAPSE 2D:26士4 mm), respectivement.

Conclusion L'induction de l'anesthésie pour le PAC ne modifie pas les paramètres de la fonction $d u$ ventricule droit fondés sur la vélocité. Il y a eu une faible diminution de la TAPSE. Les paramètres TD étaient plus bas chez les patients PAC par rapport au groupe témoin.

In the perioperative period, right ventricular (RV) contribution to overall heart function is often underappreciated. Right ventricular failure has been shown to be an independent risk factor for morbidity and mortality and a predictor of outcome in patients with left-heart failure. ${ }^{1,2}$ In a population of coronary artery bypass graft (CABG) patients with poor left ventricular (LV) function, RV dysfunction was associated with poor postoperative outcomes. ${ }^{3}$ Although it may be desirable to assess RV function preoperatively, especially in patients at risk for RV failure, this may not always be practical or possible.

The perioperative assessment of RV function can be challenging because the RV geometry is difficult to model and because poor endocardial definition prevents accurate tracing of the RV endocardium. Tissue Doppler imaging (TDI) provides a simple non-geometric assessment of regional RV function through the measurement of tissue velocities, and it is easy to acquire even in the presence of poor 2D images.

Various echo modalities have been used to assess RV function. The tricuspid annular plane systolic excursion (TAPSE) has compared favourably with RV fractional area of change (FAC). ${ }^{4,5}$ TAPSE has also predicted mortality in patients with pulmonary hypertension, but it can be affected by left ventricular (LV) function. ${ }^{5,6}$ Tricuspid annular or myocardial velocities (TAV) have also been used to assess RV function. ${ }^{7,8}$ The isovolemic acceleration (IVA) has been shown to be a load-independent measure of contractility. ${ }^{9}$ The systolic ejection velocity has compared favourably with other measures of RV function but remains a more loaddependent measure of contractility. ${ }^{9,10}$ However, it is unknown if these measures of RV function are affected by induction of general anesthesia.

This study was designed to test the hypothesis that induction of anesthesia may alter tricuspid annular parameters of RV performance in patients undergoing elective CABG surgery.

\section{Methods}

This was a prospective observational cohort study. Following approval of the research ethics board of St. Michael's Hospital and after obtaining written informed consent to the study protocol, a convenience sample of $24 \mathrm{CABG}$ patients was enrolled during the period October 11, 2007 to November 28, 2007. Exclusion criteria included patients with valvular disease, arrhythmias, LV ejection fraction (EF) less than $45 \%$, pulmonary hypertension (mean PAP > $25 \mathrm{mmHg}$ ), and more than mild tricuspid regurgitation. Nine normal volunteers were also enrolled for comparison of preinduction variables. Anesthesia was induced in the CABG patients using sufentanil 1.0 to $1.5 \mu \mathrm{g} \cdot \mathrm{kg}^{-1} i v$, midazolam 0.10 to $0.15 \mathrm{mg} \cdot \mathrm{kg}^{-1} \mathrm{iv}$, and rocuronium 1.0 to 1.5 $\mathrm{mg} \cdot \mathrm{kg}^{-1} i v$ or pancuronium 0.1 to $0.15 \mathrm{mg} \cdot \mathrm{kg}^{-1} i v$. No volatile anesthetic agent was used during the study period. Heart rate (HR) and MAP were recorded before and after induction of anesthesia. Hemodynamic data were obtained while the patient was supine with an indwelling radial arterial catheter for the MAP. A pulmonary artery catheter was used post-induction to measure the pulmonary artery pressures (PAP) and the cardiac index using a standard thermodilution technique, with measurements performed in triplicate.

Echocardiographic examinations were performed using a GE VIVID $7^{\circledR}$ system (GE, Milwaukee, WI, USA). Prior to induction of anesthesia, a transthoracic (TTE) examination was performed by a certified echocardiography technician using a GE 1.7/3.4 MHz surface probe. An apical fourchamber view was obtained with emphasis on optimizing the lateral wall of the RV. A colour tissue Doppler sector was then applied to the lateral wall of the RV, including the tricuspid annulus (Fig. 1a). The 2D sector was narrowed to ensure a colour frame rate greater than $200 \mathrm{fps}$. One loop containing at least five cardiac cycles was recorded. The measurements were performed at end-expiration. Following induction of anesthesia and prior to the insertion of the pulmonary artery catheter, an apical four-chamber view was again obtained. A colour tissue Doppler sector was applied to the lateral wall of the RV, and a loop of at least five cardiac cycles was recorded during apnea. All images were stored digitally for later offline analysis.

\section{Data analysis}

All images were analysed offline by one observer using dedicated software (Quantitative analysis, Echopac ${ }^{\mathrm{TM}} \mathrm{GE}$, Milwaukee, WI, USA). Inter-observer variability has been previously published. ${ }^{8}$ A $6 \times 6 \mathrm{~mm}$ sample volume with $30 \mathrm{msec}$ smoothing was applied to the ventricular side of the lateral tricuspid annulus and adjusted to obtain the largest systolic velocity or excursion. Tricuspid annular velocities can be separated into two distinct systolic waves, isovolemic (IV) and systolic ejection (S) waves. As previously described, the acceleration of the IV systolic wave (IVA) was measured as the dominant upslope from zero velocity to maximum IV velocity. ${ }^{8}$ The $S$ wave was measured as the tallest peak following the IV velocity 


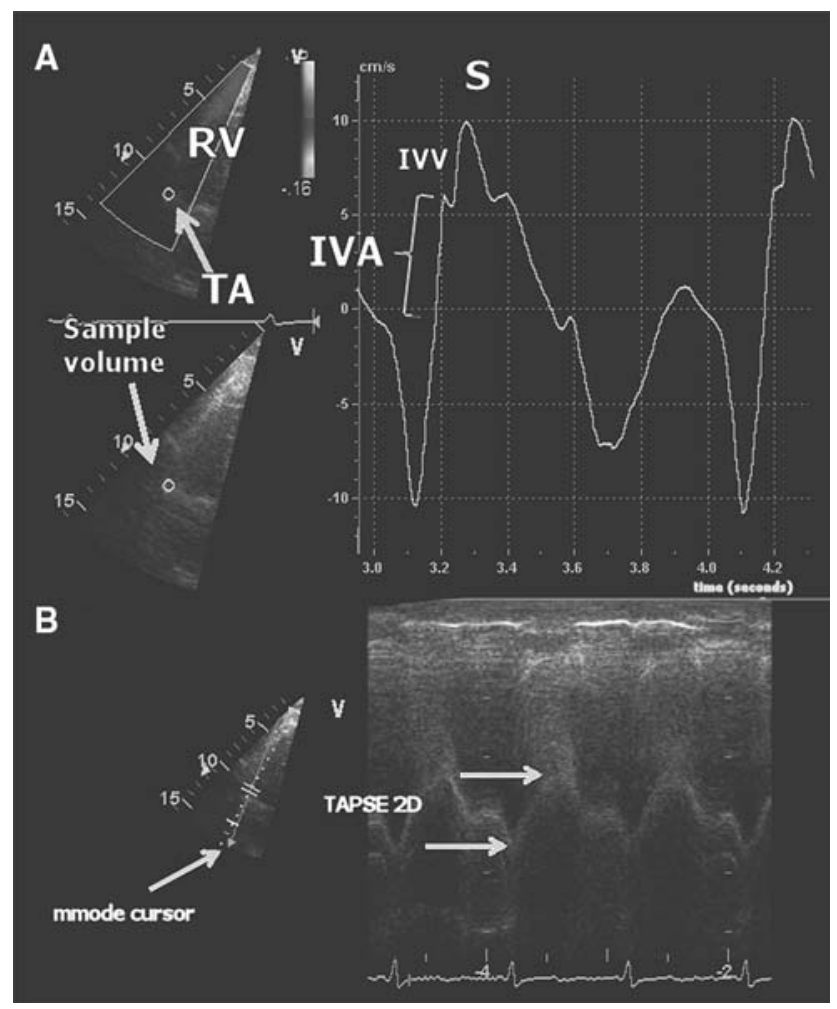

Fig. 1 Measurements of tricuspid annular velocities and excursion. a On left, 2D image of the right ventricle (RV) with reduced sector and sample volume placed at the tricuspid annulus (TA). On the right, graphical display of annular velocity over time for one heart beat. The isovolemic acceleration (IVA) is demonstrated as the upslope of the isovolemic velocity (IVV). The systolic ejection velocity (S) follows the IVV. b Anatomical M mode displayed on right drawn from 2D image on left. The TAPSE was measured as the distance travelled by the tricuspid annulus (TAPSE 2D, arrows)

(Fig. 1a). The TAPSE was measured using anatomical M-mode (Fig. 1b). The average of five consecutive cardiac cycles was used for each parameter.

\section{Statistical analysis}

In the context of this being an observational study, no formal sample-size calculation was applied. All data are expressed as mean \pm SD. A two-tailed paired Student's $t$ test was used to compare pre- and post-induction values of MAP, IVA, S, and TAPSE 2D. An unpaired Student's $t$ test was used to compare the normal group with the CABG group for the IVA and the TAPSE. A Mann-Whitney Rank Sum test was used to compare the normal group and the CABG group for both the HR and the $\mathrm{S}$ wave.

\section{Results}

Twenty-one males and three females were recruited for the CABG group, and nine healthy male volunteers were
Table 1 Demographic data for the normal patients and the coronary artery bypass graft (CABG) patients

\begin{tabular}{lll}
\hline & $\begin{array}{l}\text { Normal } \\
\text { Mean } \pm \text { SD }\end{array}$ & $\begin{array}{l}\text { CABG patients } \\
\text { Mean } \pm \text { SD }\end{array}$ \\
\hline Number & 9 & 24 \\
M/F & $9 / 0$ & $21 / 3$ \\
Height $(\mathrm{cm})$ & $171 \pm 7$ & $169 \pm 9$ \\
Weight $(\mathrm{kg})$ & $72 \pm 8$ & $83 \pm 18$ \\
Age $(\mathrm{yr})$ & $36 \pm 6$ & $64 \pm 10$ \\
\hline
\end{tabular}

Data are expressed as mean $\pm \mathrm{SD}$

recruited for the "normal" group. The demographic data are presented in Table 1. With the exception of two patients, all had clinically significant right coronary artery stenosis; however, none had a previous RCA infarction or suffered ischemia during the study period. No candidate was excluded from the study. In the CABG group, 19 patients were receiving $\beta$-adrenergic blocking drugs, 11 were receiving calcium channel blockers, three were receiving angiotensin receptor blocking agents, five were on diuretics, and nine were receiving insulin or oral hypoglycemic medications. All of the CABG patients received sufentanil and midazolam for anesthetic induction, and 18 of 24 patients received pancuronium. No normal volunteers were receiving medication.

The hemodynamic and echocardiographic data are presented in Table 2. Following induction of anesthesia, there was a significant decrease in MAP from $105 \pm 14 \mathrm{mmHg}$ to $79 \pm 12 \mathrm{mmHg}(P=0.001)$ but no change in $\mathrm{HR}(67 \pm 13$ beats $\cdot \min ^{-1}$ pre-induction and $67 \pm 9$ beats $\cdot \min ^{-1}$ postinduction). No patient required vasoactive support during the study period. The TAPSE could not be measured for one patient after induction of anesthesia due to poor 2D imaging. There was no significant change between pre- and postinduction regarding either the IVA $\left(1.63 \pm 0.61 \mathrm{~m} \cdot \mathrm{sec}^{-2}\right.$ vs $\left.1.84 \pm 0.83 \mathrm{~m} \cdot \mathrm{sec}^{-2}\right)$ or the $\mathrm{S}$ wave $(8.80 \pm 1.23$ $\mathrm{cm} \cdot \mathrm{sec}^{-1}$ vs $\left.9.0 \pm 1.92 \mathrm{~cm} \cdot \mathrm{sec}^{-1}\right)$. However, there was a significant decrease in TAPSE $(23 \pm 3.6 \mathrm{~mm}$ vs $21 \pm 3.8$ $\mathrm{mm}, P=0.039$ ) following induction of anesthesia.

The data for the normal $v s$ the CABG patients are presented in Table 2. Whereas mean HR values were similar between the normal and the CABG patients, the mean values for IVA, S-wave, and TAPSE were all higher in the normal volunteers compared with the CABG patients.

\section{Discussion}

In this study, induction of anesthesia using sufentanil, midazolam, and either pancuronium or rocuronium did not significantly affect TAV. Annular excursion, however, was mildly decreased. Tissue Doppler parameters and TAPSE 
Table 2 Hemodynamic and tissue Doppler variables for the normal, pre- and post-induction for the coronary artery bypass group (CABG)

\begin{tabular}{llll}
\hline & $\begin{array}{l}\text { Normal } \\
\text { Mean } \pm \mathrm{SD}\end{array}$ & $\begin{array}{l}\text { Pre-induction } \\
\text { Mean } \pm \mathrm{SD}\end{array}$ & $\begin{array}{l}\text { Post-induction } \\
\text { Mean } \pm \text { SD }\end{array}$ \\
\hline HR $\left(\right.$ beats $\left.\cdot \mathrm{min}^{-1}\right)$ & $71 \pm 10$ & $67 \pm 13$ & $67 \pm 9$ \\
MAP $(\mathrm{mmHg})$ & $\mathrm{N} / \mathrm{A}$ & $105 \pm 14$ & $79 \pm 12^{*}(P=0.001)$ \\
Mean PAP $(\mathrm{mmHg})$ & $\mathrm{NA}$ & $\mathrm{NA}$ & $20 \pm 6$ \\
$\mathrm{CI}\left(\mathrm{L} \cdot \mathrm{m}^{-1} \cdot \mathrm{m}^{-2}\right)$ & $\mathrm{NA}$ & $\mathrm{NA}$ & $2.4 \pm 0.4$ \\
IVA $\left(\mathrm{m} \cdot \mathrm{sec}^{-2}\right)$ & $2.34 \pm 0.34$ & $1.63 \pm 0.61^{* *}(P=0.003)$ & $1.84 \pm 0.83$ \\
S wave $\left(\mathrm{cm} \cdot \mathrm{sec}^{-2}\right)$ & $11.14 \pm 2.78$ & $8.80 \pm 1.23^{* *}(P=0.028)$ & $9.0 \pm 1.92$ \\
TAPSE $(\mathrm{mm})$ & $26 \pm 3.7$ & $23 \pm 3.6^{* *}(P=0.019)$ & $21 \pm 3.8^{*}(P=0.039)$ \\
\hline
\end{tabular}

$H R$ heart rate, MAP mean arterial pressure, IVA isovolumic acceleration, $S$ wave systolic ejection velocity, TAPSE tricuspid annular systolic excursion, $P A P$ pulmonary artery pressure, $C I$ cardiac index

* Different from pre-induction values

** Different from normal group $(P<0.05)$

in the $\mathrm{CABG}$ population were significantly lower than those of the normal population.

Standard cardiac anesthetic induction utilizes a pharmacological strategy to produce the least possible hemodynamic disturbance while providing optimal attenuation of the hemodynamic responses to surgical stimulation. The drugs, ketamine, midazolam, etomidate, and propofol have been shown to cause myocardial depression both in animal models and in vitro. ${ }^{11,12}$ Sufentanil has been shown to mildly depress LV systolic function in a human population. ${ }^{13}$ The effect of anesthetic drugs on right-heart function has not been extensively studied and has yielded conflicting results. ${ }^{14,15}$

Overall RV performance is the result of the sum of the functions of the lateral wall, the septum, and to some extent the participation of the LV. ${ }^{5,16-18}$ The longitudinal function of the free wall of the RV can be assessed using tissue Doppler echocardiography. Tricuspid annular descent or TAPSE has been shown to correlate with RV FAC, but is influenced by LV function., ${ }^{4,5}$ Values above $20 \mathrm{~mm}$ have been associated with normal biventricular function. ${ }^{5}$

The pre-ejection period has also been used to assess right-heart function using variables such as $\mathrm{dP} / \mathrm{dt} .{ }^{19}$ During this period, myocardial motion can be observed; however, if this period is truly isovolemic, no motion should be detectable. In contrast to $\mathrm{dP} / \mathrm{dt}$, pre-ejection myocardial velocities may therefore result from the combination of myocardial changes required to close the tricuspid valve, conformational changes in the non-contractile elements, or atrial relaxation. ${ }^{20}$ In an animal model, the RV IVA has been shown to be a load-independent measure of contractility. ${ }^{9}$ In a human population and when applied to the left ventricle, IVA has also been found to be preload-independent. $^{21}$ The tricuspid annular IVA reflects the inotropic state of the RV at the time of examination. It has, however, been shown to be HR-dependent. ${ }^{22,23}$

The $\mathrm{S}$ wave velocity is a load-dependent measure of contractility, ${ }^{9}$ which represents the maximum myocardial ejection velocity achieved under the prevailing load conditions and contractility. The myocardial $\mathrm{S}$ velocity reflects the rate of work of the particular segment of myocardium under current conditions. ${ }^{24}$

The effect on induction of anesthesia on tricuspid annular motion and velocity

As assessed by colour tissue Doppler echocardiography, induction of anesthesia did not alter TAV. There was no significant change in IVA at equivalent HR suggesting no negative inotropic effect. The $\mathrm{S}$ wave did not change following induction of anesthesia; however, there was a slight decrease in TAPSE. As RV function is partly dependent on LV function, the decrease in TAPSE may have been related to a decrease in work by the LV, as there was a significant decrease in MAP. Furthermore, the decrease in TAPSE may not have been clinically relevant. Indeed, significant reductions in RV FAC and RV stroke volume index have only been observed at TAPSE less than $18 \mathrm{~mm} .^{6}$ Although we did not measure CVP and PAP prior to induction of anesthesia, the small decrease in TAPSE may have resulted, at least in part, from the small decrease in SV due to small alterations of preload or afterload. The unchanged velocities and acceleration would suggest no alteration in the inotropic state of the RV.

\section{Comparison between normal volunteers and CABG} patients

All velocity-based TDI parameters of RV function and TAPSE were lower in the CABG group when compared with the normal group at equivalent HR. All TAPSE values exceeded the previously reported threshold of $18 \mathrm{~mm}$ for depressed RV function, as measured by FAC. ${ }^{6}$ The TAPSE in the normal group compared well with the values reported 
in the literature. ${ }^{4,5,25}$ There were no data for comparison for the IVA, as it has not been extensively studied in the lateral wall of the RV using colour TDI. Nikitin et al. examined RV basilar myocardial S velocities using colour TDI in normal patients in various age groups. ${ }^{26}$ They found a value of $9.26 \pm 2.28 \mathrm{~cm} \cdot \mathrm{sec}^{-1}$ in the group aged 20 to 39 and a value of $7.56 \pm 2.49 \mathrm{~cm} \cdot \mathrm{sec}^{-1}$ in the group aged 60 to 79 . These values are slightly lower than our healthy control group (11.14 \pm 2.28$)$ and our cardiac patients $(8.80 \pm 1.23$ $\left.\mathrm{cm} \cdot \mathrm{sec}^{-1}\right)$. This small discrepancy may have resulted from sampling in the myocardium at a more apical location than in our study (velocities decrease progressively toward the apex) where the cursor was placed to obtain the maximum $\mathrm{S}$ wave velocity (as close as possible to the annulus).

The different findings in the CABG $v s$ the normal patients may have reflected mildly diminished RV and/or LV systolic function in the CABG patients. The widespread use of $\beta$-blocking drugs and calcium channel blocking drugs in the cardiac surgery population may have had an additional effect on the IVA and S wave velocity. Indeed, esmolol has been shown to decrease IVA. ${ }^{9}$ Differences in age between groups may also have contributed to these findings, as myocardial velocities have been shown to decrease with age. ${ }^{26}$

There are several limitations of our study. Since our routine practice does not include invasive monitoring of patients prior to induction of anesthesia, we could not assess the impact of changing preload and afterload as a result of induction of anesthesia on RV function. The RV is sensitive to afterload, more specifically the PAP. It is unlikely that induction of anesthesia would have caused a significant increase in PAP. Furthermore, a reduction in PAP would not be expected to cause a reduction but rather an increase in TAPSE, which did not occur. Additionally, the RV does not respond to preload in the same way as the $\mathrm{LV}$. The RV can accommodate larger volumes of blood without significant increases in surface area; for this reason, little increase in diastolic wall stresses are observed during the induction sequence. ${ }^{27}$ It follows that there would be little recruitment in inotropy following preload alterations. The decreases that were observed in TAPSE suggested SV reduction, likely the result of either mild preload reduction or a decrease in LV work as a result of the reduction in MAP. These changes would not have affected contractility. We did not observe changes in annular velocities.

As commonly occurs, the RV endocardial border could not be traced accurately in a large number of patients due to poor RV endocardial definition; thus, we did not have another objective measurement of RV function, such as EF or FAC with which to compare our results.

The precision in measurements of TAPSE using anatomical M-mode was dependent on the resolution of the $2 \mathrm{D}$ image. Marginal images may have precluded precise measurements. Furthermore, velocity measurements and TAPSE may have been influenced by tethering, translation, and rotation.

Although this study examined only the regional longitudinal function of the RV free wall, it is likely that any significant changes in global RV function would be reflected in this area. The differences observed in myocardial velocities between the normal volunteers and CABG patients may have been related to the use of $\beta$ and calcium channel blocking drugs or, alternatively, right coronary artery disease. It is possible that age differences may have also played a role. Our population did not include patients with pulmonary hypertension or known significant pre-existing RV or LV dysfunction. Whether similar results could be obtained in this population remains to be determined.

In conclusion, induction of anesthesia using sufentanil, midazolam, and either pancuronium or rocuronium for patients undergoing CABG surgery does not affect TAV, as assessed using transthoracic TDI at the lateral wall of the RV. Significantly, the IVA remained unchanged suggesting no impact on inotropy. There was, however, a small nonclinically significant decrease in TAPSE. All measures of TAV and TAPSE were lower in the CABG patients when compared to the normal group, possibly due to the effects of $\beta$ and calcium channel blocking drugs or cardiac disease.

Funding sources None.

Competing interests None declared.

\section{References}

1. Ghio $S$, Tavazzi L. Right ventricular dysfunction in advanced heart failure. Ital Heart J 2005; 6: 852-5.

2. Ghio S, Gavazzi A, Campana $C$, et al. Independent and additive prognostic value of right ventricular systolic function and pulmonary artery pressure in patients with chronic heart failure. J Am Coll Cardiol 2001; 37: 183-8.

3. Maslow AD, Regan MM, Panzica P, Heindel S, Mashikian J, Comunale ME. Precardiopulmonary bypass right ventricular function is associated with poor outcome after coronary bypass grafting in patients with severe left ventricular systolic dysfunction. Anesth Analg 2002; 95: 1507-18.

4. Lopez-Candales A, Rajagopalan N, Gulyasy B, Edelman K, Bazaz $R$. Comparative echocardiographic analysis of mitral and tricuspid annular motion: differences explained with proposed anatomicstructural correlates. Echocardiography 2007; 24: 353-9.

5. Lopez-Candales A, Rajagopalan N, Saxena N, Gulyasy B, Edelman $K, B a s a z$. Right ventricular systolic function is not the sole determinant of tricuspid annular motion. Am J Cardiol 2006; 98: 973-7.

6. Forfia PR, Fisher MR, Mathai SC, et al. Tricuspid annular displacement predicts survival in pulmonary hypertension. Am J Respir Crit Care Med 2006; 174: 1034-41. 
7. Saxena $N$, Rajagopalan $N$, Edelman $K$, Lopes-Candales A. Tricuspid annular systolic velocity: a useful measurement in determining right ventricular systolic function regardless of pulmonary artery pressures. Echocardiography 2006; 23: 750-5.

8. David JS, Tousignant CP, Bowry $R$. Tricuspid annular velocity in patients undergoing cardiac operation using transesophageal echocardiography. J Am Soc Echocardiogr 2006; 19: 329-34.

9. Vogel M, Schmidt MR, Kristiansen SB, et al. Validation of myocardial acceleration during isovolumic contraction as a novel noninvasive index of right ventricular contractility: comparison with ventricular pressure-volume relations in an animal model. Circulation 2002; 105: 1693-9.

10. Wang J, Prakasa K, Bomma C, et al. Comparison of novel echocardiographic parameters of right ventricular function with ejection fraction by magnetic resonance. J Am Soc Echocardiogr 2007; 20 : 1058-64.

11. Stowe DF, Bosnjak ZJ, Kampine JP. Comparison of etomidate, ketamine, midazolam, propofol, and thiopental on function and metabolism of isolated hearts. Anesth Analg 1992; 74: 547-58.

12. Nonaka A, Kashimoto S, Imamura M, Furuya A, Kumazawa T. Mechanism of the negative inotropic effect of midazolam and diazepam in cultured foetal mouse cardiac myocytes. Eur J Anaesthesiol 1997; 14: 481-7.

13. Miller DR, Wellwood M, Teasdale SJ, et al. Effects of anesthetic induction on myocardial function and metabolism: a comparison of fentanyl, sufentanil and alfentanil. Can J Anaesth 1988; 35: 219-33.

14. Boyd O, Murdoch LJ, Mackay CJ, Bennett ED, Grounds RM. The cardiovascular changes associated with equipotent anaesthesia with either propofol or isoflurane. Particular emphasis on right ventricular function. Acta Anaesthesiol Scand 1994; 38: 357-62.

15. Kellow NH, Scott AD, White SA, Feneck RO. Comparison of the effects of propofol and isoflurane anaesthesia on right ventricular function and shunt fraction during thoracic surgery. Br J Anaesth 1995; 75: 578-82.

16. Hoffman D, Sisto D, Frater RW, Nikolic SD. Left to right ventricular interaction with a noncontracting right ventricle. J Thorac Cardiovasc Surg 1994; 107: 1496-502.

17. Klima UP, Lee MY, Guerrero JL, Laraia PJ, Levine RA, Vlahakes $G J$. Determinants of maximal right ventricular function: role of septal shift. J Thorac Cardiovasc Surg 2002; 123: 72-80.
18. Damiano RJ Jr, La Follette P Jr, Cox JL, Lowe JE, Santamore $W P$. Significant left ventricular contribution to right ventricular systolic function. Am J Physiol 1991; 261: H1514-24.

19. Kanzaki H, Nakatani S, Kawada T, Yamagishi M, Sunagawa K, Miyatake $K$. Right ventricular $\mathrm{dP} / \mathrm{dt} / \mathrm{P}(\max )$, not $\mathrm{dP} / \mathrm{dt}(\max )$, noninvasively derived from tricuspid regurgitation velocity is a useful index of right ventricular contractility. J Am Soc Echocardiogr 2002; 15: 136-42.

20. Veyrat $C$, Larrazet $F$, Pellerin D. Renewed interest in preejectional isovolumic phase: new applications of tissue Doppler indexes: implication to ventricular dyssynchrony. Am J Cardiol 2005; 96: 1022-30.

21. Dalsgaard M, Snyder EM, Kjaersgaard J, Johnson BD, Hassager $C$, $O h J K$. Isovolumic acceleration measured by tissue Doppler echocardiography is preload independent in healthy subjects. Echocardiography 2007; 24: 572-9.

22. Vogel M, Cheung MM, Li J, et al. Noninvasive assessment of left ventricular force-frequency relationships using tissue Dopplerderived isovolumic acceleration: validation in an animal model. Circulation 2003; 107: 1647-52.

23. Tousignant CP, Miller AL, Denault A, Zhu L, Bowry R. The effect of heart rate on tricuspid annular velocities in cardiac surgical patients with atrial fibrillation. J Cardiothorac Vasc Anesth 2008; 22: 565-9.

24. Diffe GM, Chung E. Altered single cell force-velocity and power properties in exercise-trained rat myocardium. J Appl Physiol 2003; 94: 1941-8.

25. Hammarstrom E, Wranne B, Pinto FJ, Puryear J, Popp RL. Tricuspid annular motion. J Am Soc Echocardiogr 1991; 4: 131-9.

26. Nikitin NP, Witte KK, Thackray SD, de Silva R, Clark AL, Cleland $J G$. Longitudinal ventricular function: normal values of atrioventricular annular and myocardial velocities measured with quantitative two-dimensional color Doppler tissue imaging. J Am Soc Echocardiogr 2003; 16: 906-21.

27. Greyson $C R$. Pathophysiology of right ventricular failure. Crit Care Med 2008; 36(1 Suppl): S57-65. 